\title{
Emotional Intelligence as the Basis for the Development of Organizational Leadership During the Covid Period (Educational Institution Case)
}

\author{
INNA SEMENETS-ORLOVA ${ }^{1}$, ALLA KLOCHKO ${ }^{2}$, TETIANA SHKODA ${ }^{3}$, OLENA MARUSINA ${ }^{4}$, \\ MARIIA TEPLIUK ${ }^{5}$ \\ ${ }^{1}$ Department of Public Administration, INTERREGIONAL ACADEMY OF PERSONNEL MANAGEMENT, UKRAINE. \\ E-mail: innaorlova@ukr.net \\ ${ }^{2}$ Advanced Distributed Learning Center, NATIONAL DEFENCE UNIVERSITY OF UKRAINE NAMED AFTER IVAN \\ CHERNIAKHOVSKYI, UKRAINE. \\ ${ }^{3}$ Department of Personnel Management and Labour Economics, VADYM HETMAN NATIONAL ECONOMIC \\ UNIVERSITY, UKRAINE. \\ ${ }^{4}$ Department of Foreign Languages, TARAS SHEVCHENKO NATIONAL UNIVERSITY OF KYIV, UKRAINE. \\ ${ }^{5}$ Department of Business Economics and Entrepreneurship, VADYM HETMAN NATIONAL ECONOMIC \\ UNIVERSITY, UKRAINE.
}

\begin{abstract}
The period of coronavirus disease pandemic caused new challenges in leadership development and reflected transition to collective leadership as the most effective method. Because (emotional) unity of the corporate team (which is practically realized in collective leadership) is a primary factor for overcoming the crisis, human resources will be saved as much as possible in this context. The use of emotional intelligence tools and organizational leadership development becomes highly relevant. The emphasis is placed on the fact that organizations' adaptive, innovative activities and online work lead to new trends in the leadership development paradigm. However, most managers are not ready to apply them. The case study of an educational organization shows numerical indicators of the emotional intelligence levels of managers and essential characteristics of their emotional literacy. It is found out that less than half of managers can ensure employees' psychological safety with the help of emotional intelligence. It is emphasized that leaders can quickly change the climate of their teams and have the most significant impact on the psychological security of organizations. Leadership development can bring additional dividends in times of instability. So coronavirus disease pandemic increases management decentralization trends.
\end{abstract}

Keywords: pandemic, collective leadership, empathic communication, emotional intelligence

JEL Classification: D23, 121 


\section{Introduction.}

The epidemic period and coronavirus outbreak caused most companies in the public and private sectors to work remotely. Digital technologies change the nature of leadership. Communication tools form virtual collaboration and mix several multimedia modes in one environment. So each member of the organization can participate in the management of the company and communicate with colleagues, customers, and partners. This fact updates the problem of organizational leadership and its development. Virtual reality makes people more vulnerable, so "soft skills" and emotional intelligence (EI) become crucial for online communication. Participants of the meeting do not sit in the same room anymore, so nonverbal clues cannot help to understand each other better. In the paper, the main factors of collective leadership are highlighted. The role of managers' emotional intelligence is presented.

Currently, public servants are expected to have emotional awareness, communicate effectively to citizens, and know public law and policies. Emotional intelligence is a valuable asset among leaders. Leaders cannot expect employees to change if they are not inspiring individuals. Emotional intelligence can shape workplace success. They show adaptability to innovations and act as changemakers; emotionally intelligent leaders present their ability to change. Only then do leaders get credibility among followers, and suggested changes are readily accepted.

The situation of coronavirus outbreak actualized the need for qualitative remote work. It has become a contributing factor in the development of organizational leadership. Technologies have significantly reduced dependence on centralization. In interpersonal relations such as education, effective interaction could provide a high quality of services. Emotional leadership has become increasingly crucial for an institution's ability to have clients in the crisis period. As a result, managers with developed EQ turned out to be the most successful.

\section{Literature review.}

Transformational leadership became the basis for the concept of organizational leadership in 1994. Transformational leadership ensured the identification of all employees with the organization/community. J. McGregor Burns was the first scientist who presented the "transformational leadership" concept and contrasted it with the concept of "transaction leadership" $[10,41]$. This researcher believed that transformational style creates tremendous positive changes in the followers' life as they focus on achieving high levels of morality and motivation $[10,43]$. Their followers have confidence, enthusiasm and obeisance to managers, want to do more than planned. Changes in the organization are grounded on a joint vision and purpose. On the other side, "transaction leadership" has such traditional management approaches as a problem statement and performance control. Transformational leaders use such instruments of influence as identification and vision (similar to strategic leadership, but the latter concept is vastly grounded on new public management principles); appropriate working model, team values, performance management, intellectual stimulation. According to some authors, transformational leadership can satisfy demands for leaders in learning organizations [16]. Transformational leaders impact organizations' fundamental beliefs and values and create the reality that allows achieving the company's aims (Table 1). Researchers believe that this leadership style provides higher performance compared to transactional leadership [49, 408].

Many modern foreign scientists derive new theories of leadership from the concept of transformative leadership. Transformational leadership can be defined as an essential phenomenon of knowledge society and economies built on companies creating knowledge [6] and using it intensively (knowledge-intensive companies) [42].

According to Braja Deepon Roy, organizational leadership is a managerial approach in which managers help to set the organization's strategic goals while inspiring people to fulfill the task to achieve these goals effectively [40]. 
Table 1. Approaches to defining organizational leadership (definitions)

\begin{tabular}{|c|c|}
\hline Definition of the concept of executive leadership & Author of the concept \\
\hline $\begin{array}{l}\text { Business interrelations, which cannot be controlled by official } \\
\text { systems but require a close interpersonal network }\end{array}$ & $\begin{array}{l}\text { Kanter Rosabeth Moss } \\
\text { (Kanter, 2003) }\end{array}$ \\
\hline $\begin{array}{l}\text { Collaboration in a team where leaders can protect the process, } \\
\text { promote cooperation and can be patient in dealing with high } \\
\text { levels of disappointment }\end{array}$ & $\begin{array}{l}\text { David D. Chrislip (Chrislip, } \\
\text { 2002) }\end{array}$ \\
\hline $\begin{array}{l}\text { The distribution system of results of the activity through } \\
\text { borders between different organizations based on trust and } \\
\text { partnership }\end{array}$ & $\begin{array}{l}\text { David Archer and } \\
\text { Cameron (Archer } \quad \& \\
\text { Cameron, 2008) }\end{array}$ \\
\hline $\begin{array}{l}\text { These are focused relationships in which all parties strategically } \\
\text { decided to collaborate in achieving expected results, with } \\
\text { communication, partnership, joint engagement and democratic } \\
\text { persuasion as the primary resources }\end{array}$ & Hank Rubin (Rubin, 2009) \\
\hline $\begin{array}{l}\text { The leaders' capability to participate, cooperate with business, } \\
\text { official authorities, and the non-governmental sector ensures } \\
\text { effective management of limited resources through the } \\
\text { adoption of intelligent networking and intelligent urbanization } \\
\text { technologies }\end{array}$ & $\begin{array}{l}\text { Nick Lovegrove and Matthew } \\
\text { Thomas (Lovegrove \& } \\
\text { Matthew, 2013) }\end{array}$ \\
\hline $\begin{array}{l}\text { An active combination of individual leadership abilities } \\
\text { manifests itself at the behavioral level in the group. It is an } \\
\text { operational partner for coaching teams }\end{array}$ & $\begin{array}{l}\text { Martin Echavarria } \\
\text { (Echavarria, 2015) }\end{array}$ \\
\hline $\begin{array}{l}\text { The process of engaging collective intelligence to achieve } \\
\text { results over organizational boundaries when conventional } \\
\text { controls are lacking }\end{array}$ & $\begin{array}{l}\text { Johan Amborg (Amborg, } \\
\text { 2016) }\end{array}$ \\
\hline $\begin{array}{l}\text { Process of harmonizing the objectives of several different } \\
\text { stakeholders and harmonizing integration between and over } \\
\text { organizations to achieve them }\end{array}$ & Leonard Brock (Brock, 2017) \\
\hline
\end{tabular}

There is a need to develop an atmosphere of cooperation in the modern culture of organizational activity. To improve collaboration at all organizational levels, it is very important for managers to obtain emotional intelligence from professionals to evolve understanding and manage their emotions and other people's ones. Studies show that emotional intelligence can influence the results of activities in those companies, where the desired negotiations, cooperation and personnel cohesion are successful. It remarkably reflects the sphere of institutions' work, educational institutions and their organizational characteristics. It is also essential to maximize overall collaborative strategies based on strengths, capabilities, and aspirations $[3,66]$.

Based on the process of self-organization and self-government system, a new management paradigm presupposes the development of a new management subject - a leader of changes. Leaders of change are proactive, ready to take the initiative, attract necessary people to do the job and create effective teams. The development of leaders, who can easily collaborate the values of the company and the values of its employees, is impossible without El.

In $1990 \mathrm{~J}$. Mayer and P. Salovey suggested the emotional intelligence concept. Emotional intelligence is the people's ability to identify their own emotions and other people's emotions, distinguish and term them appropriately, apply emotional information for controlling their behavior, and manage emotions to achieve reasonable goals [30; 31]. 
According to Turkish scientists E. Altındağ and Y. Kösedağı, "innovative institution culture" in the organization as well leaders with high levels of El are significant for the institutions. Based on the data of a mass sociological study, theorists proved a significant interrelation between emotional intelligence, the culture of institutions focusing on innovations and the effectiveness of personnel's work [1].

E. Vigoda-Gadot and G. Meisler determine that those leaders, who are emotionally intelligent, show willingness and ability to changes [50]. Public servants with developed emotional intelligence are respected and trusted by employees. They are aware of employees' needs, which is critically important for followers to accept proposed changes and innovations in professional activities. According to B. Hunter [24], it is necessary to conduct more research for identifying and quantifying the strength and weaknesses of leaders with emotional intelligence. A better knowledge of the features of El can significantly improve the organization's success. The most important thing is to understand how emotionally reasonable state managers affect organizational indicators.

Greek researchers C. Arfara and I. Samanta determine that emotional intelligence has two dimensions, both of which affect the knowledge and management of emotions for public sector employees, improve the quality and comprehensiveness of performing tasks by public servants, as well as their greater openness to producing changes [5, c. 169].

According to U. Ghuman, it is necessary to develop practical tools for measuring El at the group level and evaluate its effectiveness "in predicting outcomes such as performance and learning ability" [20]. The researcher notes that emotional intelligence can contribute to an increase in group learning and group activity. Groups that form group emotional awareness and can manage emotional relationships in groups can become more productive and capable of learning.

M. Brackett, J. Mayer \& R. Warner note that a significantly more considerable measure of emotional intelligence is more typical for women than for men, based on sociological research [8, 1389]. The same results are covered in the works of P.Dhani and T. Sharma showed in their works that people, who have high El, can feel "psychological well-being" at a higher level than those people who have low levels of El $[15,180]$

In the researches of A. Cazan, L. Năstasă, the interrelation of such factors as emotional intelligence, burnout and life satisfaction is revealed. These authors convince that El is connected with better adaptation or success in an unstable context and conditions of changes. Besides, highlevel El is related to a lower level of anxiety, stress, and a higher level of life satisfaction [11, 1575].

In the research by K. Schlegel, it is argued that emotional abilities, but not general mental abilities, provide for the results of negotiations. The researcher theoretically supports the statement that knowledge and perception of the other persons' emotions should be considered fundamental in interpersonal communication in negotiations. The consequence of this is a better receipt of information that further allows negotiators to use these emotions management strategies [43, 7].

After all, it is not possible to control emotions effectively if they have not been precisely established. As N. Schutte notes, higher emotional intelligence is significantly connected with improving mental health, significant work, great pleasure in social support in the workplace and a greater sense of freedom and self-worth in the workplace [44, 138].

According to J. Rode, emotional intelligence helps employees develop interpersonal communication, relationships, and leadership qualities more strongly, leading to higher financial compensation. The researcher concluded a significant, positive effect of emotional intelligence on wages. And it includes 1 ) mediation by the presence of a mentor; 2) a more powerful effect at a higher level of organization management $[38,78]$. The researcher claims that El is helpful for employees in getting the required social capital to succeed in their career development.

Z. Ouyang's work determines that emotional intelligence can significantly affect job satisfaction. It is highlighted a close interrelation among emotional intelligence, the pleasure of "organizational justice" and "professional happiness" of employees [35, 149]. 
According to J. Limonero, emotional intelligence mainly declines negative moods and increases positive ones, helps restore strength. People with a higher level of emotional assistance are more favorable $[27,816]$. It affects people's minds and has an essential role in restoring the generation of positive thoughts [30], or positive memories can be an option for our case. Therefore, it helps develop emotional abilities connected with components of emotional understanding to cope with adverse situations effectively.

It is stated that managers' emotional intelligence correlates positively with their satisfaction with the work of their subordinates.

J. McCleskey argues that new leaders will demand such skills, which let them address the challenges of increased diversity, heterogeneity of working groups, high level of ambiguity, and the necessity of more personalized approaches (McCleskey, 2015). Modern leaders require skills, which can be precisely related to El.

Another scientist J. Mayer justifies the concept of the perspective of the analysis of emotional intelligence of mental ability [29, 292].

Quite interesting is the research of R. McFarlin. Based on the theory of evaluation of emotions, the researcher and colleagues found that emotional intelligence can reduce the harmful effect of role stress on emotional exhaustion and ambiguities connected with changes [34, 109].

Emotional intelligence is based on self-awareness. The self-esteem of leaders affects their decision-making, responsibility, activities and initiatives. Persons, who have a high level of El, are socially responsible, demonstrate more positive relationships, and are more susceptible than those who have a low level of El.

The research has used P. Hall's technique, according to which respondents were offered thirty statements about five parameters of emotional intelligence: emotional awareness, management of personal emotions, self-motivation, empathy and management of emotions in a team (Hall \& West, 2011).

Leadership is the ability to influence people individually and have an impact on the whole team. 20-30\% of an organization's effectiveness depends on the atmosphere in a group, $50-70 \%$ of it depends on leaders' mood and behavior. A competent leader can direct emotions towards achieving the company's goals, inspire employees, motivate them for self- development, and boost a team's performance $[8,781]$.

At the Davos International Economic Forum - 2016, there was a report on "The Future of Jobs" that identified emotional intelligence as an essential skill for managers and as a "soft skill" for all employees of the company. In the list of ten skills of the future emotional intelligence has a sixth place [21].

\section{Generalization of the main statements.}

Key findings within the study indicated that public managers with high levels of emotional intelligence were self-aware and could help others with transformational leadership.

Transformational leadership contains the latest concepts of collective (collaborative), organizational, strategic and situational leadership. It can be schematically depicted as follows (Figure 1).

Organizational leadership forms the so-called collective intelligence to achieve results across administrative boundaries. It is an increasingly important source of competitive advantage in modern business environments focused on team and partnership. Organizational leadership involves the developed capacity of leaders to build dynamic networks and then increasingly requires collaborative cultures to use the knowledge and expertise of all stakeholders for innovation and their effective collaboration [19]. 
Figure 1. Modern types of leadership

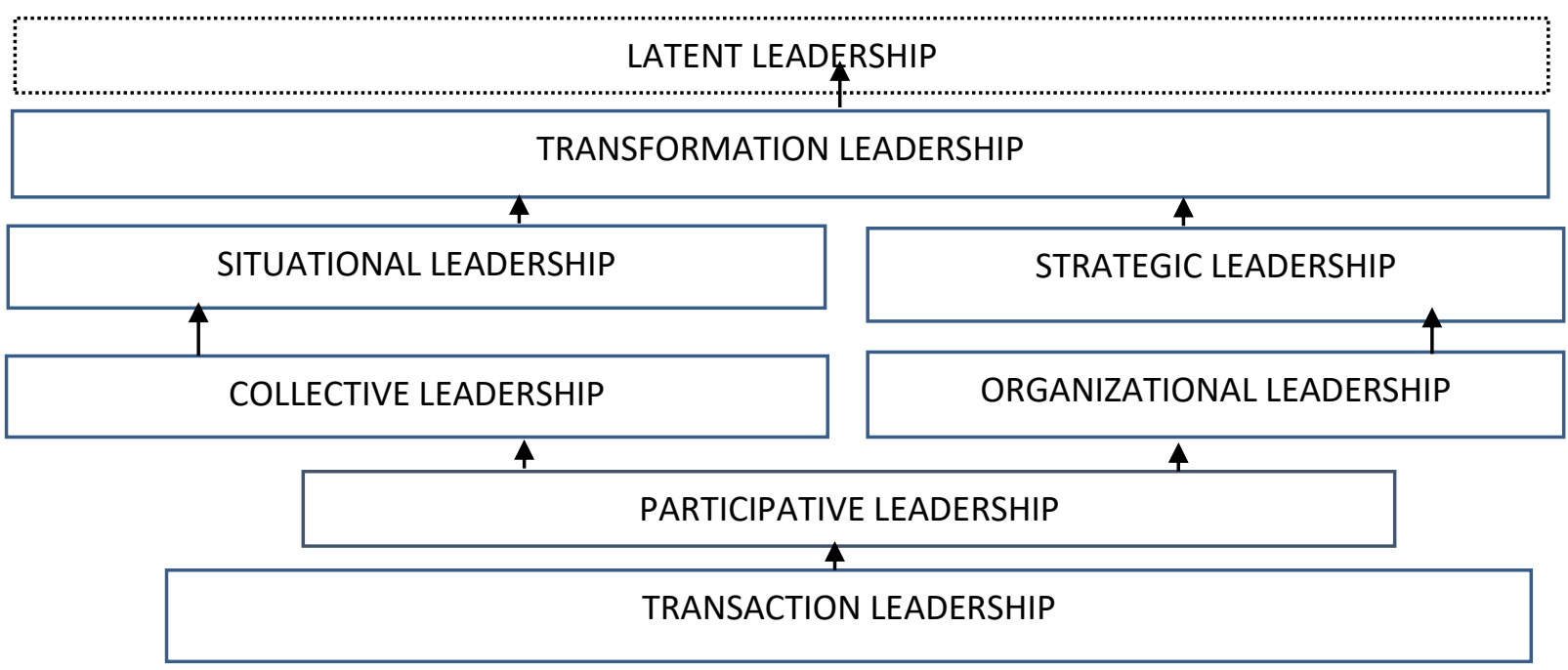

Source: Constructed by the authors.

Transformational leadership is effective in organizations of various types, including educational ones [36]. Based on this definition, organizational leadership can be defined as a relationship with the nature of close cooperation between the leader and the organization's staff, institution and the process of moving towards a legitimized common goal. Therefore, organizational leadership presupposes the presence of a leader (obviously, formal as well as informal, but ideally it should combine formal and informal at the same time is one person or one group of persons) and the employees of the institution and organization who support him/them (Table 2).

Table 2. Comparison of the classic approach to defining leadership and organizational (collective) leadership

\begin{tabular}{|l|l|}
\hline A classic approach to defining "leadership" & $\begin{array}{l}\text { The latest approach to defining "leadership" } \\
\text { - collective/organizational leadership }\end{array}$ \\
\hline Statement of tasks & Promoting knowledge diffusion \\
\hline $\begin{array}{l}\text { Instruments of influence: encouragement, as } \\
\text { well as the ability to order and use the } \\
\text { authority of a position }\end{array}$ & $\begin{array}{l}\text { Reference power (based on respect for and } \\
\text { capture of the leader, in psychological } \\
\text { identification with the leader) }\end{array}$ \\
\hline More vertical character & $\begin{array}{l}\text { More horizontal character (organization } \\
\text { manager + line managers) }\end{array}$ \\
\hline Operational orientation & Development orientation \\
\hline Command and control methods & Advisory methods and broad collegiality \\
\hline $\begin{array}{l}\text { One important function is to provide resources for processes and necessary organizational } \\
\text { activities }\end{array}$ & $\begin{array}{l}\text { Increasingly non-template and non-traditional } \\
\text { leadership practices }\end{array}$ \\
\hline $\begin{array}{l}\text { Management approaches of paradigm the public management } \\
\text { new }\end{array}$ & Expert government \\
\hline Authority government & $\begin{array}{l}\text { Mobile team of specialists highly suitable for } \\
\text { project work }\end{array}$ \\
\hline $\begin{array}{l}\text { Leader as an individual with legal } \\
\text { competencies and legitimized competencies } \\
\text { (the level of professional readiness of the } \\
\text { leader is highly appreciated by subordinates) }\end{array}$ & \\
\hline $\begin{array}{l}\text { Focus on the unique professional abilities of } \\
\text { the leader }\end{array}$ & Active organizational training \\
\hline Continuous process monitoring & Intellectual stimulation and self-organization \\
\hline
\end{tabular}


Collective leadership, first of all, is embodied in the triangle of power, business and civil society. It can be argued that this concept is materially broader than organizational leadership, as, for example, it more implies an element of direct democracy in the management of local affairs [39].

Collective leadership (which according to various approaches can meaningfully include the type of organizational leadership) and executive leadership has several indispensable attributes:

1) the motivations of leaders are balanced, for whom the desire to create social value is a priority, regardless of where they work combining political, economic reasons with the motives of socially significant affairs [47];

2) distributive nature of skills and skill of the leader as quantitative analytics, strategic planning and management of interested parties (stakeholder management);

3) contextual intelligence is an element from the realm of situational leadership, involves empathy between different sectors, taking into account a wide language, cultural contexts in the processes of managing key performance indicators (performance management) [22];

4) networks of relations between sectors involved in the implementation of activities are integrated (networking) [25];

5) personal readiness to pursue a career in the public sector [23];

6) men have a stronger ambition to become a manager in academia than women [48];

7) the ability to carry out a holistic examination from a specific three-brunch issue (civil society, power, business), understanding and properly evaluating the arguments on each sector. It requires a developed network for regular cooperation between the three sectors, systematic discussions for the reality of a consensus style of decision-making.

In the 21st century, the central concept of the introduction of collective (organizational) leadership is quality assurance, including the quality of public services, as we mentioned earlier.

Four components influence the formation and development of leadership in an educational institution in their relationship: the motives for achieving personal and collective goals, the leader's behavior, the influence of the leader on the group, and the group's effect on the leader. Educational managers can implement measures to form and develop collective leadership using situational leadership algorithms [49].

According to the survey of 15,000 leaders (the results of a study by DDI), IQ wins complex rounds of decision-making in business, especially in an area where financial intelligence is required. But in rounds aimed at people, the development of networks and teams, EQ dominates. According to research, financial literacy requires $98 \%$ IQ and $2 \% \mathrm{EQ}$. But the group work is $38 \% \mathrm{IQ}$ and $62 \% \mathrm{EQ}$ [13].

To determine the levels of expression of the leadership type, the managers used the questionnaire "Are you a leader or a manager?" [18]. The period of the study was 2019, and it covered educational institutions from five regions of Ukraine. The number of the survey's respondents is 253 heads of educational institutions.

The study results showed that the bulk of managers have an average level of severity of the leadership type (43\%). The low level of seriousness of the leadership type is typical for $38 \%$. $19 \%$ showed a high degree of expression (Figure 2). They are characterized by seeing the situation as a whole, managing subordinates, the ability to motivate and convince others.

When change becomes the only possible stability, flexibility becomes an essential organizational characteristic. Very conditionally, all processes in the company can be divided into two profiles. In English sources, they are called "run" (in this case, it is appropriate to translate this word as "exploitation") and "change" ("changes"). Most employees today hone their competencies in the first place: they become good performers, and then managers who work within the framework of established processes. The problem, especially in large companies, is a severe imbalance between these two functions. People of the "run" profile are precious to the company. However, to provide 
flexibility, it is necessary to systematically increase the share of employees of the "change" profile, those who will understand when it is time to change, bring fresh ideas, and develop new models. "People-changes" often cannot manage stable, well-tuned processes, so it's about balance, not substitution. There are also situations when you do not need to "rebuild" good managers: it is better to attract young specialists to the processes of change or find in your team those who will be interested at first.

Figure 2. Levels of leadership type of managers

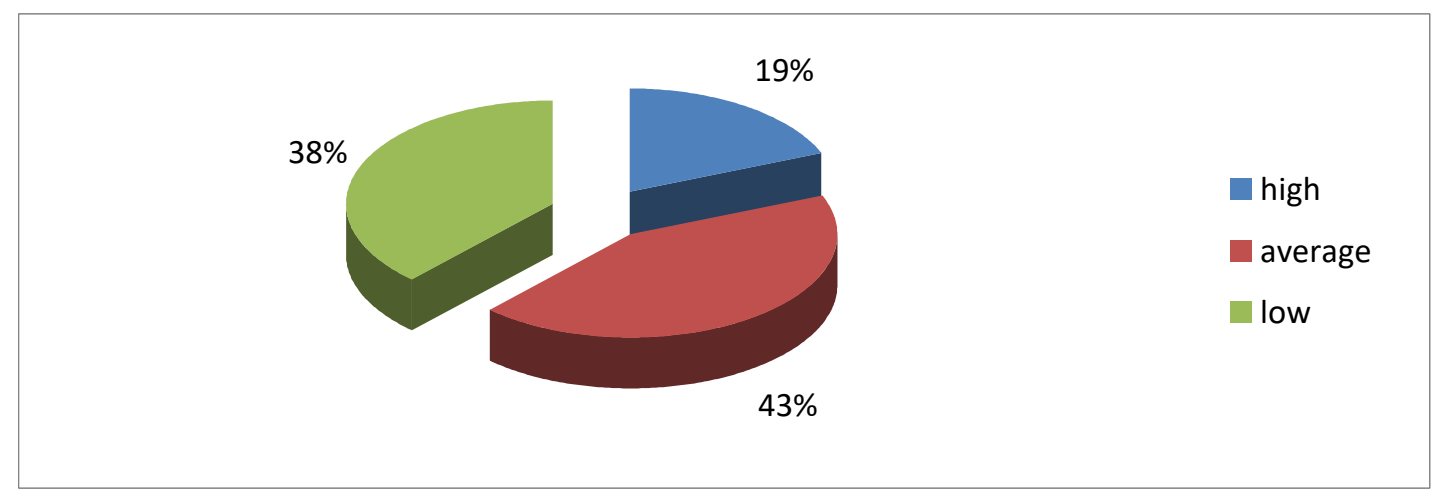

Source: Constructed by the authors based on a questionnaire of 253 heads of educational institutions in Ukraine (author's survey, 2019)

Today a variable culture of labor requires a lot from the leaders of organizations. Technological advances have brought many instruments of social cooperation, but at the same time, a volatile work environment makes it difficult. For example, take the case of the covid-19 crisis. We are all aware of the situation and how it doomed the economy. The business went remotely, employees suffered from stress, anxiety and still suffer, many sectors were wholly lost, and the rest are dealing with its consequences. It isn't easy to maintain the organizational culture at the proper level while workers work at home. It is difficult to provide employees with intellectual support and motivate them at this difficult time.

The quarantine situation has proved the fact that employees need to acquire new skills to operate successfully.

Leaders can show emotional intelligence by:

1) taking the initiative in crisis management. In the absence of strategic planning, urgent measures should be taken to overcome obstacles;

2) working to preserve organizational community - empathy can partially compensate the lack of "live" communication in times of virtual communication;

3 ) being flexible and adaptive - the immediate reaction of the manager to the crisis was to work at home and use remote control tools available on the market;

4) constant communication. Excellent communication skills are necessary for effective leadership. The leader must be able to share knowledge and ideas of urgency and enthusiasm. If the leader cannot deliver messages, the reactions of employees will be adverse. There should be a lot of communication, especially informal ones. Effective communication can solve many problems that cannot be solved. Organizational leaders who listen and hear, form trust and goodwill in the organization;

5) trying to stabilize the organization and overcome the current crisis, looking for opportunities under challenging restrictions;

6) staying long-sighted - overcoming anxiety, creating a convincing picture of the future that inspires others to persevere, introducing new models of activity that will determine plans.

For better cooperation at all organizational levels, professionals must receive EI - the capability to manage their own emotions and other people's ones [14]. The study shows that emotional intelligence can influence the effectiveness of organizations, especially in those where successful 
negotiations and cooperation are desirable. Higher levels of El improve collaboration and integration of ideas. The research of John Donald Cox recommends methods for enhancing abilities in team members, which can ultimately improve team efficiency and collaboration. It had shown the maximum effect of emotional intelligence on cooperation when teams consisted of individuals with more than one year of leadership experience and team experience. With the growth of Els, the ability to collaborate in an online environment has also significantly increased.

Based on the responses, characterizing respondents' agreement with the proposed statements, indicators of the level of emotional intelligence and its components were calculated. 98 heads of educational institutions took part in the Ukrainian survey in 2019.

The results showed that $72 \%$ of managers possess low levels of emotional intelligence, $22 \%$ average levels, and only $6 \%$ have high levels of emotional intelligence (Figure 3 ).

Figure 3. General indicator of the level of managers' emotional intelligence

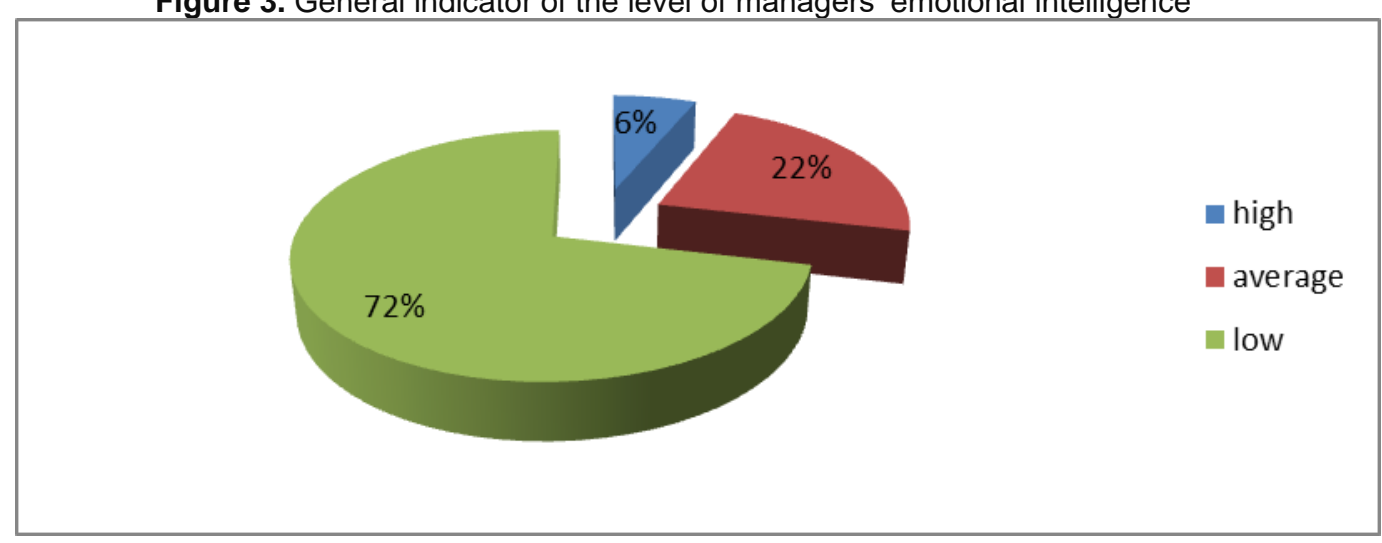

Source: Constructed by the author based on a questionnaire of 98 heads of educational institutions in Ukraine (author's survey, 2019)

Development stages of managers' emotional intelligence are presented below (Fig. 4). The first parameter is empathy, which is understanding other people's emotions and support them. Empathy helps to identify employees' problems and solve them by satisfying their needs. The average level of empathy is typical for $44.4 \%$ of managers, low - for $35.5 \%$ and high - for only $20.1 \%$.

The results were similar in terms of Self-motivation and Management of emotions in a team. Almost half of the respondents showed low levels, less than $15 \%$ - high. Self-motivation provides the ability to control behavior according to the correct management of personal emotions. Management of emotions in a team is a capability to influence the team's emotional state. It is possible to achieve the company's mission by controlling the emotions and motivation of a team.

As for Emotional awareness, low and medium levels were demonstrated by $42.3 \%$ and $46.3 \%$ of respondents and high - by $11.4 \%$ of managers. Emotional awareness implies the ability to interpret emotions correctly, understand reasons and evaluate emotional states. 
Figure 4. Levels of development of managers' emotional intelligence

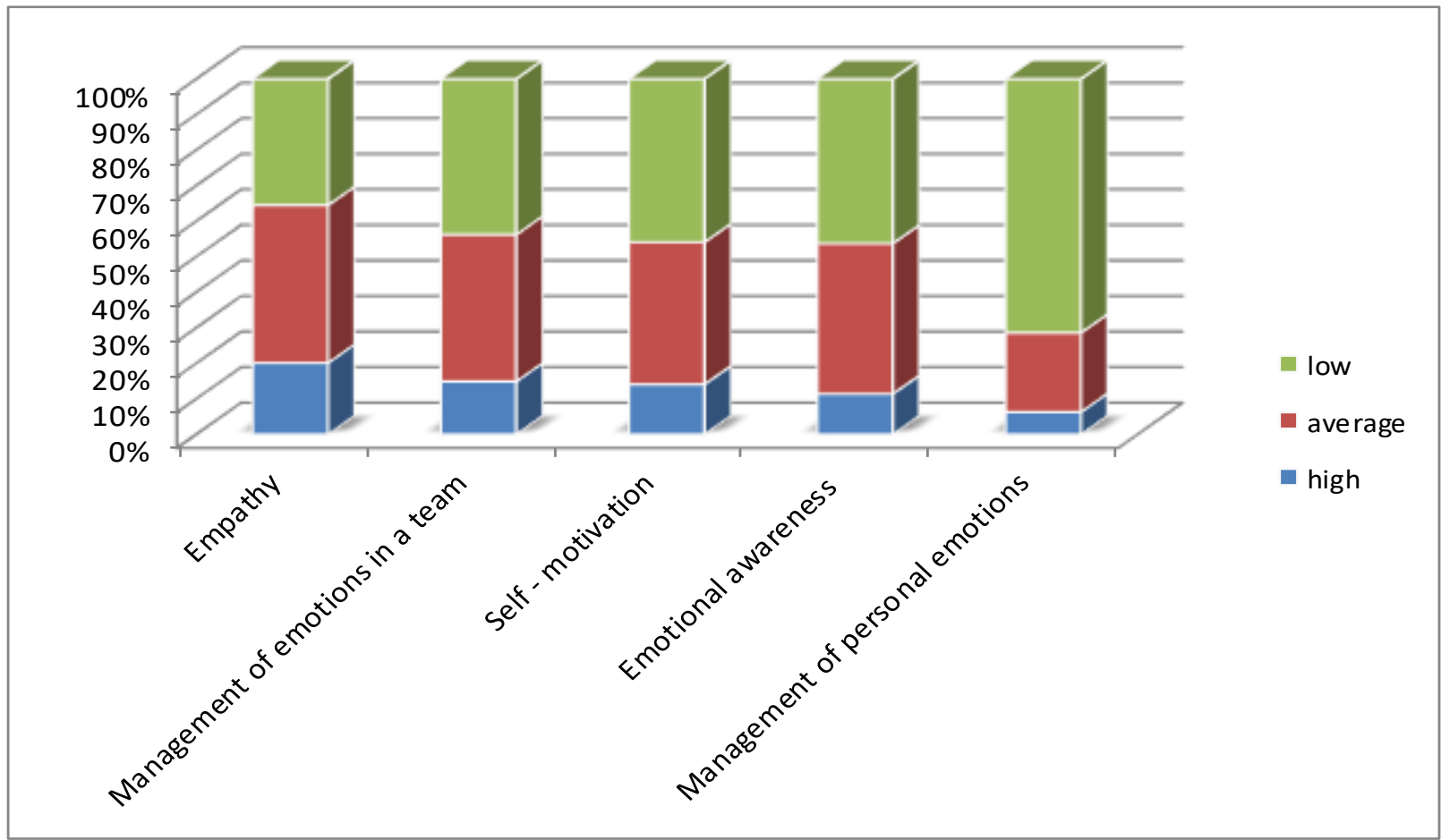

Source: Constructed by the authors based on a questionnaire of 98 heads of educational institutions in Ukraine (author's survey, 2019)

The most problematic parameter of emotional intelligence is the management of personal emotions, which is understood as emotional flexibility, the ability to control personal emotions and create necessary emotional states. $71.4 \%$ of managers demonstrate low results for this parameter, while only $6.3 \%$ show high results.

\section{Discussion.}

The concept of leadership in a broad sense reflects the relationship between a leader and members of a group (or other social community) that exercises mutual influence on each other in the process of moving towards a common goal.

Managers' emotional intelligence provides opportunities to have a substantial impact on employees (Figure 5).

Self-understanding. Leaders must possess high levels of emotional intelligence to manage their teams effectively, have a friendly atmosphere at work and bring people together for a synergistic effect. Leaders should be motivated by the company's mission and desire to take the initiative.

Figure 5. Team management and the leader

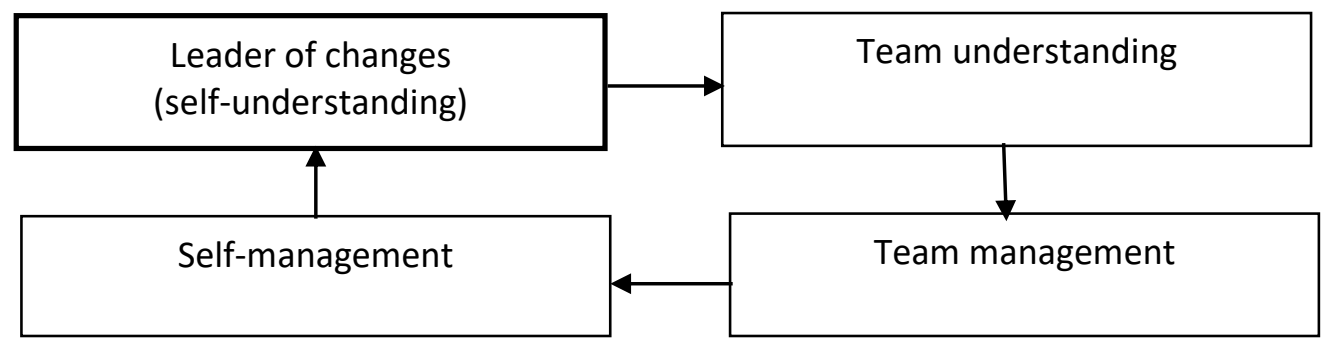

Source: Constructed by the authors.

Self-management. Since self-motivation is considered an essential El parameter, leaders should look for incentives to help them perform at work efficiently, improve qualification levels, be an example for their teams, and do their job correctly. 
Team-understanding. Awareness of people's motives can help leaders understand the needs, desires and interests of their teams better.

Team-management. The high emotional intelligence of leaders allows them to make necessary changes in their teams. To achieve high performance at work and increase the competitiveness of the company, leaders must be able to boost the intellectual and creative abilities of the group. Considering some external changes and the particular needs of workers, leaders of changes should create appropriate working conditions for the team to achieve high productivity levels. Only such kinds of groups are ready for changes and implementation of new ideas.

So self-organization mechanism of a company starts with its leaders - leaders of changes managers who are aware of their role and ready to show initiative and team- understanding.

Leaders who rely on expert power contribute to the formation and development by members of their teams of specific behavioral skills and qualities critical in the information age and are essential for acquiring knowledge [37, 209]. These are the so-called "leaders who give knowledge" (knowledge-enabled leaders), which, based on their role as "ministry," is meaningfully similar to the expression "servant leaders."

The reflection effect of emotional intelligence can be observed when people of the same group (colleagues, sports team, company of friends) while staying together start working in the same way. People get infected with emotions.

Most of all, people become infected with emotions from the leader. In the discussion, most even refer to his words. But it is worth noting that it can be both an official leader and an unofficial one not the director of the company, but the most popular employee. $20-30 \%$ of the effectiveness of the organization depends on the atmosphere in the team, and the atmosphere in the team the $50-70 \%$ depends on the leader, his mood and behavior [46]. 4 emotional intelligence skills are specially developed in talented leaders: thirst for achievements, initiative, skills of cooperation and teamwork, the ability to lead a team.

Dissonant leaders cannot emotionally synchronize with the team and count their emotions to find the right words. Large organizations have to distribute leadership among the leaders of various departments, turns them into a team. Leaders must constantly cooperate, not just everyone doing their job.

Good leaders have different styles: ideological, mentoring, kind and democratic, radical and commanding. All of them can be used depending on the situation. A deep conversation with a subordinate, which goes beyond the limits of current affairs, and in return, is aimed at knowing a person's life, including his dreams, goals and career plans, is unrealistic for building trusting relationships in a team. The mentor should have an interest in subordinates and speak with them at least 20 minutes a week. The leader with developed emotional intelligence, as a rule, will joke four times more than a regular employee.

Mentor leaders help their subordinates understand their strengths and weaknesses and set clear goals. Employees work more effectively when their personal goals echo those of the organization. A good leader-mentor develops employees. He/she gives them not only routine work but also a challenging task. His/her message: "I believe in you, I invest in you [time, knowledge, patience, etc.], I expect the best from you". A good leadership style involves an open expression of emotions and feelings. Showing emotions and feelings, the leader demonstrates humanity. Workers see him/her as a real person. It is crucial in certain situations.

\section{Conclusion.}

The study results show that the majority of managers have an average level of organizational leadership (43\%). $38 \%$ of managers have low levels of it. Only $19 \%$ showed high levels of corporate leadership. The emphasis is placed on the fact that organizations do not fully use leadership 
resources. Being a vital resource, it needs to be built and developed during the coronavirus disease pandemic.

In times of crisis, leaders are expected to show courage, commitment, responsibility for their decisions and final results, transparency, involvement and understanding of all stakeholders (crisis leadership).

From the customer's point of view, leaders need to show accountability. It is also essential to create a positive atmosphere and "psychological security" for employees. Emotional intelligence is the tool that can help develop organizational leadership, become innovative, take advantage of diversity, and adapt to changes. These potential opportunities are more important in times of crisis caused by the COVID-19 pandemic. However, only a small number of managers (43\%) demonstrate positive behavior that can create a "psychological security" climate.

The paper develops the concept that management styles change from traditional "command and control" (authoritarian leadership) to organizational and advisory leadership during the crisis. Different approaches to the problem can ensure a positive atmosphere in a team. The current situation shows that $56 \%$ of leaders need support in leadership development. So instead of a onetime training program, a system of leadership development should be used. Organizations need to develop ways to make emotional intelligence a part of leaders' daily activities.

Leaders should invest time and other resources in open and compassionate conversations lost during the pandemic (empathic communication). It is a problem of organizational health. Communication functions of organizations need to become more flexible. It is established that emotional intelligence develops leadership and contributes to practical innovations, experiments, flexibility and increases the overall effectiveness of organizations.

\section{Acknowledgment.}

This paper is performed as a part of the research project "Realization of the young scientists' potential in integration of science, education, and business" (State registration № 0120U102126), which is publicly funded by the Ministry of Education and Science of Ukraine.

\section{References}

1. Altındağ, E., Kösedağı, Y. (2015). The relationship between emotional intelligence of managers, innovative corporate culture and employee performance. Procedia-Social and Behavioral Sciences, 210, 270-282.

2. Amborg, J. (2016). Collaborative Leadership, Oxford leadership, White paper

3. Anand, R., \& Udayasuriyan, G. (2010). Emotional intelligence and its relationship with leadership practices, International Journal of Business and Management, 5(2), 65- 71.

4. Archer, D. \& Cameron, A. (2008). Collaborative leadership - how to succeed in and interconnected world. Butterworth Heineman.

5. Arfara, C., \& Samanta, I. The impact of emotional intelligence on improving team-working: the case of Public Sector (National Centre for Public Administration and Local Government-NCPALG). Procedia-Social and Behavioral Sciences, 2016, v. 230, pp. 167-175.

6. Barkhordari, S., Fattahi, M., \& Azimi, N. (2018). The Impact of Knowledge-Based Economy on Growth Performance: Evidence from MENA Countries. Journal of the Knowledge Economy, 1-15.

7. Brackett, M. A., Mayer, J. D., \& Warner, R. M. (2004). Emotional intelligence and its relation to everyday behaviour. Personality and Individual Differences, 36(6), 1387-1402. https://doi.org/10.1016/S0191-8869(03)00236-8. 
8. Brackett, M., Rivers, S., Shiffman, S., Lerner, N. \& Salovey P. (2006). Relating emotional abilities to social functioning: A comparison of selfreport and performance measures of emotional intelligence, Journal of Personality and Social Psychology, 91. 780-795.

9. Brock, L. (2017). Rochester-Monroe anti-poverty effort more than collaboration. Democrat and Chronicle.

10.Burns MacGregor J. (2003). Transforming Leadership: A New Pursuit of Happiness, Atlantic Monthly Press.

11.Cazan A.M., \& Năstasă L.E. (2015). Emotional intelligence, satisfaction with life and burnout among university students. Procedia-Social and Behavioral Sciences, 180, 1574-1578.

12.Chrislip, D. (2002). The collaborative leadership fieldbook, Jossey-Bass.

13.Collins, Dennis. (2016). EQ vs IQ: Which is Best for Collaborative Leadership? Resolution Leadership, DDI's leadership skills research report, https://www.ddiworld.com/research/leadership-skills-research.

14.Cox, J. \& Cole, M. (2016) Emotional Intelligence and Collaboration: Implications for Teams. Proceedings, https://doi.org/10.5465/ambpp.2016.13299.

15.Dhani, P., \& Sharma, T. (2017). Effect of Emotional Intelligence on Job Performance of IT employees: A gender study. Procedia computer science, 122, 180-185.

16.Dobbs, R., Walker, P. (2010). Transformational Leadership: A Blueprint for Real Organizational Change, Dobbs Leadership.

17.Echavarria, Martin. (2015). Enabling Collaboration - Achieving Success Through Strategic Alliances and Partnerships, LID Publishing Inc.

18.Fetiskin, N. (2005). Socio-psychological diagnosis of the development of personality and small groups, Moscow, Publishing House of the Institute of Psychotherapy.

19.Fischer, S. (2016) Transformational leadership in nursing: a concept analysis, https://doi.org/10.1111/jan.13049.

20.Ghuman, U. (2016), An empirical examination of group emotional intelligence in public sector workgroups, Team Performance Management, Vol. 22 No. 1/2, pp. 51-74. https://doi.org/10.1108/TPM-02-2015-0010.

21.Gray, A. (2016). 10 skills you need to thrive in the Fourth Industrial Revolution. URL: https://www. weforum.org.

22. Holovatyi, M. (2014). Multiculturalism as a means of nations and countries interethnic unity achieving. Economic Annals-XXI, 11-12, 15-18.

23.Hubanova, T., Shchokin, R., Hubanov, O., Slobodianiuk, P., \& Drobotov, S. (2020). Special criminological principles of crime prevention in the field of intellectual property. International journal of management, Volume 11, Issue 7, 938-952.

24.Hunter, B., Dizon, J., Napoles, C. \& Rubalcava, F. (2020). The Impact of Emotional Intelligence in The Public Sector, Procedia - Social and Behavioral Sciences, 10.13140/RG.2.2.23925.12002.

25.latsyshyn, A., Kovach, V., Lyubchak, V., Zuban, Y., Piven, A., Sokolyuk, O., latsyshyn, A., Popov, O., Artemchuk, V. \& Shyshkina, M. (2020), Application of augmented reality technologies for education projects preparation, CEUR Workshop Proceedings.

26.Kanter, Rosabeth Moss (2003). Rosabeth Moss Kanter on the Frontiers of Management, Harvard Business Review, Harvard Business School Press.

27.Limonero, J. T., Fernández-Castro, J., Soler-Oritja, J., \& Álvarez-Moleiro, M. (2015). Emotional intelligence and recovering from induced negative emotional state. Frontiers in psychology, 6, 816. 
28.Lovegrove, N. \& Matthew, Th. Why the World Needs Tri-Sector Leaders, Harvard Business Review, 2013, 2, https://hbr.org/2013/02/why-the-world-needs-tri-sector.html

29.Mayer, J. D., Caruso, D.R., \& Salovey, P. (2016). The Ability Model of Emotional Intelligence: Principles and Updates. Emotion Review, v. 8 (4), pp. 290-300.

30.Mayer, J. D., \& Salovey, P. (1990). Emotional intelligence. Imagination, Cognition, and Personality, 9, 185-211.

31. Mayer, J. D., \& Salovey, P. (1997). What is emotional intelligence? In P. Salovey, D. J. Sluyter (Eds.). Emotional development and emotional intelligence: Educational implications (3-34). Harper Collins: New York.

32. Mayer, J., \& Salovey, P. (1995). Emotional intelligence and the construction and regulation of feelings. Applied and preventive psychology, 1995, v. 4, № 3, pp. 197- 208.

33.McCleskey, J. (2015) An examination of the relationship between ability model emotional intelligence and leadership practices of organizational leaders and entrepreneurs. Dissertation, Capella University, Minneapolis.

34.McFarlin, R., Rode J., \& Shervani T. (2015). A contingency model of emotional intelligence in professional selling. Journal of the Academy of Marketing Science, v. 44 (1), pp. 108-118.

35.Ouyang, Z. (2015). Organizational justice and job insecurity as mediators of the effect of emotional intelligence on job satisfaction: A study from China. Personality and Individual Differences, 2015, v. 76, pp. 147-152.

36.Pereira, T., Neto, M., \& Victorino, G. (2017). Information and Knowledge-Intensive Firm: Uncovering Information Flows at Amorim Cork Composites using Social Network Analysis. ICISDM '17.

37.Politis, J. (2005). The influence of managerial power and credibility on knowledge acquisition attributes, Leadership \& Organization Development Journal. 26 (3), 197-214.

38.Rode, J. C., Arthaud-Day, M., Ramaswami, A., \& Howes, S. (2017). A time-lagged study of emotional intelligence and salary. Journal of Vocational Behavior, 101, 77-89.

39. Romanenko, Y. O. (2016). Place and role of communication in public policy. Actual Problems of Economics, 176(2), 25-26.

40.Roy, B. (2020) Organizational Leadership in the Time of Covid-19, available at: https://blog.vantagecircle.com/organizational-leadership/.

41.Rubin, H. (2009). Collaborative Leadership: Developing Effective Partnerships for Communities and Schools. Corwin Press.

42.Rylander, A., \& Peppard, J. (2005). What Really is a Knowledge-Intensive Firm? (Re)framing Research in the "Knowledge Economy".

43.Schlegel, K., Mehu, M., van Peer, J. M. \& Scherer, K. R. (2018). Sense and sensibility: The role of cognitive and emotional intelligence in negotiation. Journal of Research in Personality, 74, 6-15.

44.Schutte, N. (1998). Development and validation of a measure of emotional intelligence. Personality and individual differences, 25, № 2, pp. 167-177.

45.Schutte, N., \& Loi N. (2014). Connections between emotional intelligence and workplace $\mathrm{fl}$ ourishing. Personality and Individual Differences, 2014, v. 66, p. 134-139.

46.Semenets-Orlova, I., Klochko, A., Nestulya, S., Mykhailych, O., \& Omelyanenko, V. (2019). Readiness of the education manage to provide the organizational development of institutions (based on the sociological research). Problems and Perspectives in Management, 17(3), 132-142. https://doi.org/10.21511/ppm.17(3).2019.11. 
47.Semenets-Orlova, I., Klochko, A., Tolubyak, V., Sebalo, L. \& Rudina, M. (2020). Functional and roleplaying positions in modern management teams: an educational institution case study. Problems and Perspectives in Management, 18(3), 129-140. doi:10.21511/ppm.18(3).2020.11.

48.Tsymbaliuk, S., Kurchenko, L., Tokar, V., Vinska, O., \& Shkoda, T. (2020). Gendered perceptions of professional development in academia: evidence from a Ukrainian university. Problems and Perspectives in Management, 18(1), 394-404. http://dx.doi.org/10.21511/ppm.18(1).2020.34.

49.Vecchio, R., Bullis, R.C., \& Brazil, D. (2006). The Utility of Situational Leadership Theory. Small Group Research, 37, $407-424$.

50.Vigoda-Gadot, E., \& Meisler, G. (2010). Emotions in management and the management of emotions: The impact of emotional intelligence and organizational politics on public sector employees. Public Administration Review, 70(1), 72-86.

51.Walter, F., Cole, M. S., \& Humphrey, R. H. (2011). Emotional intelligence: sine qua non of leadership or folderol? Academy of Management Perspective, 25, 45-59. 